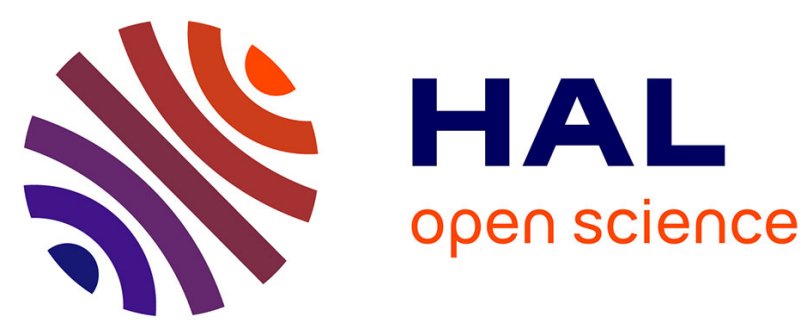

\title{
Evaluation of window flight traps for effectiveness at monitoring dead wood associated beetles: the effect of ethanol lure under contrasting environmental conditions
}

\author{
C. Bouget, H. Brustel, A. Brin, L. Valladares
}

\section{- To cite this version:}

C. Bouget, H. Brustel, A. Brin, L. Valladares. Evaluation of window flight traps for effectiveness at monitoring dead wood associated beetles: the effect of ethanol lure under contrasting environmental conditions. Agricultural and Forest Entomology, 2009, 11 (2), p. 143 - p. $152.10 .1111 /$ j.14619563.2008.00400.x . hal-00455346

\author{
HAL Id: hal-00455346 \\ https://hal.science/hal-00455346
}

Submitted on 10 Feb 2010

HAL is a multi-disciplinary open access archive for the deposit and dissemination of scientific research documents, whether they are published or not. The documents may come from teaching and research institutions in France or abroad, or from public or private research centers.
L'archive ouverte pluridisciplinaire HAL, est destinée au dépôt et à la diffusion de documents scientifiques de niveau recherche, publiés ou non, émanant des établissements d'enseignement et de recherche français ou étrangers, des laboratoires publics ou privés. 
1 Version definitive publiée dans Agricultural and Forest Entomology (2009) 11, 143 -

$2 \quad 152$

3 DOI: $10.1111 / \mathrm{j} .1461-9563.2008 .00400 . \mathrm{x}$

4

5 Evaluation of window flight traps for effectiveness at monitoring dead wood

6 associated beetles: the effect of ethanol lure under contrasting environmental

7 conditions

10 Running title: Baited window flight traps and saproxylic beetles

13 Bouget, C.(1)*, Brustel, H.(2), Brin, A.(2), Valladares, L.(2)

16 (1) Institute for engineering in agriculture and environment (Cemagref) - Research

17 Unit "Forest ecosystems" - Domaine des Barres F-45290 Nogent-sur-Vernisson

18 christophe.bouget@cemagref.fr

20 (2) Ecole d'Ingénieurs de Purpan (EIP) - 75 Voie du TOEC F-31076 TOULOUSE

21 cedex 3 herve.brustel@esa-purpan.fr, antoine.brin@esa-purpan.fr,

22 lionel.valladares@esa-purpan.fr

$24 *$ corresponding author 
26 Keywords : optimization, sampling methods, efficiency, monitoring, alcohol bait 27 
29 1. Since the species-rich group of saproxylic beetles has been proposed to be used as

30 a factor in forest management, more explicit knowledge about the efficiency and

31 selective properties of beetle sampling methods is needed.

32 2. We compared saproxylic beetle assemblages caught by alcohol-baited or unbaited

33 window traps in different forest contexts. Considering that trap attractiveness

34 depends on kairomone concentrations, we appraised whether the trap efficiency was

35 influenced by trap environment (openness and local supply of fresh dead wood).

36 3. Saproxylic beetles were sampled using 48 cross-vane window flight traps,

37 arranged in paired designs (alcohol-baited/unbaited), in 8 ancient and 8 recent gaps

38 (open stands), and 8 closed-canopy control stands in an upland beech forest in the

39 French Pyrenees.

40 4. Baited traps were more efficient than unbaited devices in terms of abundance and

41 richness in our deciduous forests. The ethanol lure did not have any repellent effect

42 on the individual response of saproxylic taxa.

43 5. The influence of local environmental conditions on trap attractiveness was

44 observed. The effects of variations in openness were actually moderate, whereas trap

45 attractiveness appeared to be reduced in the alcohol-saturated environment of recent

46 gaps due to a disruption by local fresh dead-wood concentrations of the kairomonal

47 response of saproxylic beetles to baited traps ('alcohol disruption').

48 6. Since the ethanol lure globally enhances species detection probability (no repellent

49 effect, many individual attractive effects), it may be extensively used in programs of

50 early-warning surveillance, monitoring and control of wood borers. We recommend

51 to account for the slight influences of local conditions on baited trap efficiency while

52 using them for beetle biodiversity monitoring. 


\section{Introduction}

54 Forest management practices currently include many nature conservation measures

55 in favour of fauna and flora. Nonetheless, in managed forest ecosystems, the dead

56 wood component has been severely reduced by intensive forestry and still is under-

57 represented (Siitonen, 2001).

58 Since considerable effort is devoted to preserving dead wood and the associated

59 fungi and fauna involved in the wood decaying process, we need an explicit

60 ecological assessment of the performance of forestry measures designed to increase

61 deadwood.

62 Saproxylic beetles have been widely studied over the past 20 years, especially in

63 northern and central Europe, and have been proposed as indicator species of forest

64 integrity (Speight, 1989 ; Nilsson et al., 2001) because they are highly dependent on

65 dead wood and have been particularly affected by forest management practices (e.g.

66 Siitonen, 2001 and references therein). They make up one of the largest groups of

67 red-listed species, and they represent many different functional groups (Siitonen, 68 2001).

69 As saproxylic beetles are diverse, and mainly small and cryptic, their study is very

70 challenging. If we want to use saproxylic beetles as a management tool in forestry

71 (evaluation of practices, biodiversity monitoring schemes), we need much more

72 explicit knowledge about the efficiency and selective properties of sampling

73 methods.

75 Several different methods are generally used to collect saproxylic beetles. These are

76 (i) direct active hand-collecting techniques, including peeling, sifting the bark of

77 dead trees and beating dead wood, (ii) rearing techniques (log emergence traps, 
78 Owen traps, eclectors, extraction cylinders) and (iii) trapping methods such as

79 interception or attractive (coloured, silhouette, chemo-attractive) traps (Leather,

80 2005). Window-flight trapping (WFT), also called Flight-Intercept Trapping (FIT),

81 window/ barrier trapping or collision trapping), developed by Chapman \& Kinghorn

82 Peck \& Davies, 1980), is currently the most frequently used technique for catching

83 active flying saproxylic beetles (Økland, 1996 ; Wikars et al., 2005 ; Alinvi et al.,

84 2007). Window flight traps consist of a vertical barrier to insect flight that is

85 considered invisible to the insect. On hitting the barrier, most beetles drop down and

86 fall into a collection container with liquid preservatives.

87 Although interception traps do not give accurate information about the local habitat,

88 they have proved to be satisfactory in many respects. Compared with extraction

89 methods they offer reliable means of replication and standardization, and give a

90 representative picture of saproxylic beetle fauna (Siitonen, 1994).

91

92 From the original simple model of flight-interception trap, modifications have been

93 proposed concerning the dimensions, colour, shape, bait... For instance, window-

94 flight traps may be fitted with an attractant dispenser to increase catches of dead

95 wood associated beetles (Brustel, 2004).

96 Dead wood associated species have evolved behavioral responses to volatile host-

97 plant chemicals that indicate the presence of a suitable host (i.e. kairomones). It is

98 well known that ethanol, a volatile compound released by micro-organisms in

99 decaying woody tissue (mainly in fresh tissues ; Cade et al., 1970) and stressed

100 plants (Kimmerer \& Kozlowski, 1982), acts as a foraging kairomone (used in the

101 context of food location ; Döring, 1955; Ruther et al., 2002). It is therefore attractive

102 to a wide variety of species of dead wood associated beetles (Montgomery \& Wargo, 
1031983 ; Lindelöw et al., 1992), including early- (Nordlander et al., 1986 ; Byers,

104 1989) and late-successional saproxylic species (Jonsell et al., 2003), and beetles

105 associated with dead wood from deciduous (Roling \& Kearby, 1975) or conifer trees

106 (Magema et al., 1982 ; Chénier \& Philogène, 1989).

107 Previous studies have already demonstrated the general effects of ethanol as a lure in

108 attractive window flight traps (Berti \& Flechtmann, 1986; Shibata et al., 1996). In

109 this study comparing two sampling techniques in paired designs, we first intended to

110 confirm and detail the differences in catches between alcohol-baited and unbaited

111 traps under field conditions.

112 Secondly, we wanted to assess whether the catches of dead wood associated beetles

113 in alcohol-baited or unbaited traps are influenced by local environmental conditions.

114 Indeed, we need standardized unbiased methods to study the effects of forest

115 management practices and compare open (e.g. felling areas) and closed-canopy

116 stands; ideally saproxylic beetle detectability should not change with habitat

117 structure. We thus asked the two following questions.

118 (i) Did the difference between the two methods (alcohol-baited and unbaited traps)

119 remain constant in open gaps or closed-canopy stands? From Schroeder and

120 Lindelöw (1989), release rates of chemicals are known to affect the attraction. We

121 may assume that kairomone volatility, and therefore trap attractiveness, increases

122 with stand openness. In this perspective, the difference between baited and unbaited

123 traps would be expected to be higher in open areas than in closed-canopy stands.

124 This bias variation between stands would call into question the between-stand 125 comparison using alcohol-baited traps. 
127 (ii) Did the difference between the two methods remain constant whether or not the

128 close trap surroundings were poor or rich in naturally emitted ethanol from fresh or

129 decaying dead wood?

130 We may assume that trap attractiveness is influenced by the alcohol concentration in

131 the atmosphere surrounding the trap. In recent sun-exposed gaps, the high volumes

132 of fresh dead wood release a large amount of ethanol, which may lead to a saturated

133 olfactory landscape and therefore to a reduction in the capture efficiency of the trap

134 attractant. Due to an alcohol disruption, we hypothesize that the differences between

135 paired baited and unbaited traps would be lower in recent gaps than in both old gaps

136 and forest controls where the local atmosphere is not alcohol-saturated.

\section{Material and methods}

\section{Study areas and sampling designs}

140 Our investigations were carried out in an upland beech forest in the central French

141 Pyrenees, in the National Orlu Reserve, about $150 \mathrm{~km}$ south of Toulouse. Altitude 142 ranged from $1600 \mathrm{~m}$ to $1750 \mathrm{~m}$. The selected plots were 100 to 140 year-old beech

143 stands, and had previously been exploited for charcoal by coppicing.

144 The balanced sampling design included three types of stands: 8 ancient gaps, 8 recent 145 gaps (open stands) and 8 forest controls (closed-canopy stands). The 16 gaps were 146 originally dedicated to the monitoring of conservation measures in favour of the

147 Western capercaillie (Tetrao urogallus, L. 1758). Ancient and recent gaps were 148 created in 1999 and 2004 respectively; they were circular in shape and ca 0.05 ha in 149 area. Distance between gaps varied from $80 \mathrm{~m}$ to $1000 \mathrm{~m}$. Cut trees were left in all 150 gaps but only recent gaps had high amounts of recent (freshly-cut) dead wood. In 151 parallel, a transect of 8 forest control plots was set up in closed-canopy beech stands, 
152 where the cover was quite dense (basal area $=23 \mathrm{~m} / \mathrm{ha}$, stem density $=300 \mathrm{stems} / \mathrm{ha}$,

153 mean $\mathrm{dbh}=25 \mathrm{~cm}$, mean height $=15 \mathrm{~m}$ ) and the understory very poor.

\section{Beetle sampling}

155 Beetles were sampled with a multidirectional Polytrap ${ }^{\mathrm{TM}}$ (Brustel, 2004), a cross-

156 vane window flight trap with a cumulative panel area of $1 \mathrm{~m}^{2}$ ((Fig. 1). For the

Fig. 1

57 preservation of insects, containers were half-filled with a salt mixture. A detergent

158 was added to reduce surface tension. Two traps were set in each plot, one baited with

159 an alcohol lure (1:10 ethanol released from a dispenser) and one unbaited trap.

160 Alcohol lure is known to attract hardwood-feeding species (Mongomery \& Wargo,

161 1983).

162 Overall, 24 pairs of Polytraps ${ }^{\mathrm{TM}}$ were set up in 2004, from May 15 to August 30 in

163 recent and ancient gaps and closed-canopy beech stands. The traps were emptied

164 every two weeks.

165 Collected specimens were stored in alcohol and we identified them to species level.

166 Several amateur entomologists helped with the identification on the following

167 families: Anobiidae, Curculionidae, Dasytidae, Melyridae, Mordellidae, Pselaphidae,

168 Scolytinae, Scraptiidae, Staphylinidae. The nomenclature follows the online

169 FaunaEuropaea database (www.faunaeur.org). We pooled the data for the entire

170 sampling period.

171

\section{Data processing}

173 The two sampling methods were compared in terms of total saproxylic beetle 174 abundance, cumulative species number per trap, family and species abundance per 175 trap (cumulated over the trapping periods). 
176 Linear mixed-model ANOVA tests (Pinheiro \& Bates, 2000) were carried out to

177 check for differences in abundance and species richness between the two trap types

178 in each paired comparison. The plot variable was classified as a spatial random effect

179 to take the pairing pattern of the sampling design into account. Some differences

180 were exceptionally tested by Wilcoxon signed-rank tests. Species and families

181 represented by fewer than 30 individuals were not tested.

182 The effects of the interaction between bait and two factors on total abundance and

183 abundance of alcohol-attracted taxa (in our data), species richness were assessed. The

184 three stand types of the study were clustered using two different grouping factors.

185 First, to study the influence of stand openness on trap attractiveness, we compared

186 the difference between paired baited and unbaited traps in open (recent and ancient

187 gaps) or closed-canopy stands. We analysed this difference through the interaction

188 effect in linear mixed-model ANOVAs (bait*openness). Second, to study the

189 influence of local fresh dead wood concentrations on trap attractiveness, we

190 examined the difference (baited - unbaited) in fresh dead-wood rich (recent gaps) or

191 poor (ancient gaps and forest controls) stands. The F-test of the interaction effect

192 (bait*stand type) in linear mixed-model ANOVAs was followed by a multiple

193 comparison post hoc Tukey test of the mean value of this difference.

194 Graphs include multipanel boxplots displaying the distribution of data according to

195 the two factors bait*environment, or simple boxplots showing the numerical

196 difference (baited-unbaited) for different environment types.

197 Non-Metric Multidimensional Scaling (NMDS) based on the Bray-Curtis 198 dissimilarity was used for pattern recognition in species composition and the 199 ANOSIM procedure was carried out to test for differences in assemblage 200 composition between trap types (Clarke, 1993). Before calculation of the Bray-Curtis 
201 distance matrix, species represented by only 1 individual were discarded and

202 abundance data were $(\ln +1)$ transformed.

203 ANOVA, NMDS and ANOSIM were performed using S.Plus 7.0.

\section{RESULTS}

206 When baited with alcohol, window flight traps were more selective: the ratio

207 (number of saproxylic beetles/number of beetles) reached 85.8\% in baited traps but 208 was only $69.4 \%$ in unbaited traps. A total of 12,211 saproxylic beetles were 209 identified during the study, including 196 species.

211 Comparison of effectiveness between alcohol-baited and unbaited traps

212 Alcohol-baited or unbaited traps significantly differed in effectiveness. The catches

213 of saproxylic beetles were significantly affected by the alcohol lure (mixed-model

214 ANOVA $\mathrm{F}_{(1,23)}=66.48, \mathrm{p}<0.0001$; Table 1). Overall, more than twice as many

215 saproxylic beetle individuals were captured in alcohol-baited traps as in unbaited 216 traps (Table 1).

Tab. 1 Similarly, significantly more saproxylic species were caught in alcohol-lured traps 218 than in unbaited (ANOVA $\mathrm{F}_{(1,23)}=68.65, \mathrm{p}<.0001$; Table 1). The richness per trap

Fig. 2

220 plot of the Bray-Curtis distance matrix between samples (Fig. 2), the species

221 composition of saproxylic beetle assemblages caught with or without an alcohol lure

222 clearly differed. Samples from baited or unbaited traps were obviously separated in 223 ordination space. This distinction was consistent with the results of the ANOSIM test

224 (10 000 permutations, $\mathrm{R}=0.65, \mathrm{p}<0.0001)$. The average Bray-Curtis dissimilarity 225 between baited and unbaited traps reached a value of $44 \%$. 
226 In accordance with this global dissimilarity, important specific differences were

227 noticed. For several families and species (Cryptophagidae (Cryptophagus spp.),

228 Staphylinidae (Paraphloeostiba gayndahensis, Aleochara sparsa), Salpingidae

229 (Rhinosimus ruficollis, $R$. planirostris, Rabocerus foveolatus)), significantly more

230 individuals were caught in baited traps than in unbaited traps (mixed-model

231 ANOVA; Table 2). Rhizophagus spp. (Monotomidae) was more abundant in baited

232 traps compared with unbaited traps, whereas Cleridae were not affected by trap bait.

233 Amongst xylophagous taxa, Scolytidae (Ernoporicus fagi, Xyloterus signatus, X.

234 domesticus, Xyleborus saxesenii) and Lymexylidae (Hylecoetus dermestoides) were

235 more abundantly caught in baited traps, whereas Cerambycidae, Anobiidae,

236 Melyridae were not sensitive to alcohol bait.

Tab. 2 No species or family was significantly more abundant in unbaited traps.

238

239 Comparison of effectiveness between alcohol-baited and unbaited traps in open

240 or closed-canopy stands

241 The difference between alcohol-baited and unbaited traps in open (gaps) or closed-

242 canopy stands may be interpreted first in terms of abundance or species richness. As Fig. 3 shown in figure 3, saproxylic beetle abundance in both baited and unbaited traps was

244 higher in open sites than in closed-canopy controls. The difference in abundance

245 between baited and unbaited devices was only slightly higher in open plots; in other

246 words, the bait-openness interaction effect was quite moderate (mixed-model

247 ANOVA test $\left.\mathrm{F}_{2,21}=5.17, \mathrm{p}=0.015\right)$.

248 The difference in species richness between baited and unbaited traps was not

249 significantly influenced by the openness of trap environment (Fig. 3: mixed-model

250 ANOVA test of the bait-openness interaction effect: $\mathrm{F}_{2,21}=3.23, \mathrm{p}=0.060$ ). 
252 For several taxa noticed to be sensitive to the alcohol attractant (see above), i.e.

253 Monotomidae, Scolytidae and Lymexylidae as a whole, the difference baited-

254 unbaited was not affected by the environment closure. Two families

255 (Cryptophagidae, i.e. Cryptophagus spp., and Salpingidae), and 4 species (Rabocerus

Fig. $4 \$ 6$ foveolatus, Rhinosimus ruficollis, Rhinosimus planirostris, Aleochara sparsa)

257 showed a significant difference baited-unbaited, but not in compliance with the

258 hypothesis of a bait-openness interaction. The difference was indeed lower in open

259 stands than in closed-canopy plots (fig. 4). Only the bark beetle species Xyloterus

260 domesticus showed a significant and higher difference baited-unbaited in open

261 stands.

262 In conclusion, the difference between alcohol-baited and unbaited traps was not

263 increased greatly by the openness of trap environment.

265 Comparison of effectiveness between alcohol-baited and unbaited traps in fresh

266 dead wood poor or rich stands

267 Regarding this potential bait-environment interaction effect, the difference between

268 alcohol-baited and unbaited traps was only slightly influenced by the local volume of

269 fresh woody debris releasing alcohol kairomones. The baited-unbaited difference in

270 fresh dead wood poor (ancient gaps and controls) or rich stands (recent gaps) was

271 examined in terms of total abundance, species richness, family and species

272 abundances.

273 In figure 5, the difference between baited and unbaited lures in terms of abundance

Fig. 5

274 and species richness seems to be slightly lower in gaps rich in recent fresh dead

275 wood. Nevertheless, this bait-environment interaction effect was only slightly 
276 significant on saproxylic beetle abundance (mixed-model ANOVA, $\mathrm{F}_{2,35}=4.84, \mathrm{p}=$

277 0.014). The only significant pairwise difference was observed between ancient and

278 recent gaps (Multiple comparison Tukey test), the difference being larger in ancient

279 gaps. This bait-environment interaction did not significantly affect species richness

280 in traps (mixed-model ANOVA, $\mathrm{F}_{2,35}=1.66, \mathrm{p}=0.204$ ).

Fig. 6

A bait-environment interaction effect was observed on the abundance of several families and species known to be sensitive to the ethanol attractant (fig. 6). The

283 baited-unbaited differences were lower in recent gaps than in ancient gaps and forest

284 controls for the abundance of Salpingidae (and the species Rhinosimus ruficollis in

285 particular) (multiple comparison Tukey test). Similarly, we observed a smaller yet

286 still significant baited-unbaited difference for the abundance of Cryptophagidae and

287 Rhinosimus planirostris in recent gaps compared with closed-canopy stands. For

288 Rabocerus foveolatus, Aleochara sparsa, Xyloterus signatus, the difference was less

289 in recent gaps than in closed-canopy controls (but the difference between ancient or

290 recent gaps was not significant). No difference was measured for Scolytidae as a

291 whole (and Xyloterus domesticus, Ernoporicus caucasicus, Xyleborus saxesenii in

292 particular), Lymexylonidae, Staphylinidae (peculiarly Paraphloeostiba gayndahense)

293 and Monotomidae (Rhizophagus spp. in particular).

294

295 Discussion

296

297 Alcohol lure effect

298 The results from our study confirm that ethyl alcohol, acting as a kairomone released

299 from decaying woody tissues, strongly attracts some beetles associated with dead

300 hardwood (Montgomery \& Wargo, 1983) and suggests that an ethanol lure 
301 strengthens the effectiveness of window-flight traps in deciduous forests. Indeed, 302 more than twice as many saproxylic beetles, representing a $40 \%$ higher species 303 richness, were captured in alcohol-baited traps as in unbaited traps. Assemblages

304 were globally dissimilar between baited and unbaited devices, mainly because more 305 species were caught in baited traps. It is very important to stress that we did not 306 detect any species or family significantly more abundant in unbaited traps. We may 307 therefore infer that the ethanol lure did not have any inhibiting or repellent effect.

309 In our methodological approach in beech forests, the individual responses of dead-

310 wood taxa to alcohol lure were actually heterogeneous. As previously demonstrated

311 by Byers (1992), significantly more individuals of Rhizophagus spp. (Monotomidae)

312 were caught in baited traps than in unbaited traps. Host tree chemicals are known to

313 be important to Rhizophagus species in finding their habitat (scolytid galleries).

314 Conversely, natural enemies such as Cleridae were not affected by trap bait in our

315 study. Likewise, Schroeder (2003) pointed out that two Thanasimus clerid species

316 preying on several bark beetle species differ in their response to $\alpha$-pinene and

317 ethanol. Our results showed that the abundance of ambrosia and bark beetles was

318 about 4 times as high in alcohol-baited traps, in agreement with previous findings

319 (Magema et al., 1982 ; Berti \& Flechtmann, 1986 ; Poland et al. 2004). Amongst the

320 other wood-feeding taxa, Cerambycidae were not sensitive to alcohol bait, which had

321 been shown previously by Sweeney et al. (2004). Conversely, Döring (1955)

322 demonstrated that ethanol acts as a kairomone for the longhorned beetle Cerambyx 323 cerdo. Among the fungus feeders, unlike Tetratomidae, Melandryidae and Ciidae, 324 only Cryptophagidae were significantly attracted by the alcohol lure, as was the 325 tenebrionid studied by Jonsell et al. (2003). 
327 Interaction effects between trap attractant and trap environment

328 Some results did not comply with the hypothesized bait-openness interaction. Five

329 species showed a significant lower baited-unbaited difference in open areas.

330 Moreover, the baited-unbaited difference in species richness and in abundance of the

331 other alcohol-attracted taxa was not significantly influenced by the openness of trap

332 environment. Only the total saproxylic beetle abundance and the abundance of the

333 bark beetle Xyloterus domesticus were in accordance with the hypothesis of an

334 increased baited-unbaited difference in open areas compared with closed-canopy

335 stands. In other words, trap attractiveness appeared to increase only slightly, but not

336 significantly, with stand openness, even though canopy cover may strongly influence

337 kairomone volatility. However, such an interaction effect was reported by Honek

338 (1988), between crop density and an attractant in pitfall traps, on catches of epigaeic

339 arthropods.

341 Apart from openness, another environmental factor separated the plots into groups.

342 Indeed, recent gaps, ancient gaps and forest controls differed in terms of local

343 volume of fresh dead wood. We hypothesized that the high volume of fresh dead

344 wood in recent sun-exposed gaps would release a large amount of ethanol, which

345 could saturate the beetle's olfactory landscape around the traps and therefore reduce

346 trap attractiveness. In accordance with this hypothesis, the baited-unbaited difference

347 was lower in recent and fresh dead wood rich gaps for some assemblage parameters.

348 Though this bait-environment interaction was slight, it significantly affected the total

349 abundance of saproxylic beetles, the abundance of several families and species

350 known to be sensitive to the ethanol attractant (Salpingidae, Rhinosimus ruficollis 
351 and Rhinosimus planirostris in particular, Cryptophagidae). Conversely, the response

352 of species richness and abundance of the other families (such as Scolytidae) to traps

353 was not influenced by the local volume of fresh dead wood.

354 The alternative hypothesis of a "mass effect", i.e. a stronger attractiveness of baited 355 traps in the alcohol-rich atmosphere of recent gaps, was thus invalidated. These

356 results may be related to a phenomenon that could be called 'alcohol disruption' (in

357 the spirit of the 'mating disruption'; Ruther et al., 2002), i.e. the disruption by local

358 fresh dead-wood concentrations of the kairomonal response of saproxylic beetles to

359 baited traps. Nonetheless, even though trap attractiveness appeared to be reduced in

360 an alcohol-saturated environment, baited traps remain more efficient than unbaited

361 devices in terms of abundances and richness. They have the capacity to sample the

362 pool of saproxylic beetles in recent gaps.

364 Conclusion - Implications for saproxylic beetle sampling

365 Even though the extrapolation of our findings from upland forests to other climatic 366 contexts should be done with care, their interpretation may help with the 367 optimization of the two types of forest beetle monitoring.

368 The first type, i.e. monitoring and control of forest pest populations and early369 warning surveillance programs to detect invasive wood borers, aim at maximizing 370 detection probability. We demonstrated that the ethanol lure does not have any 371 repellent effect but significantly attracts several wood feeders. Like the New Zealand 372 monitoring programme for invasive wood-feeders (Brockerhoff et al., 2006), 373 effective sampling designs may use the large spectrum of ethanol attractiveness.

374 The second type, i.e. biodiversity surveys of saproxylic beetle diversity in monitoring 375 networks or evaluation studies of forest management practices, implies distinct 
376 constraints. To compare the biodiversity between stands or to assess trends in

377 saproxylic beetle diversity over broader landscapes, ideally saproxylic beetle

378 detectability should not change with habitat structure. A variation in trap efficiency

379 as a function of any stand environmental parameter would call into question an inter-

380 site comparison. For instance, a relation between trap efficacy and stand openness

381 would prevent the comparison of open (e.g. felling areas) and closed-canopy stands

382 with alcohol-baited traps, or studies on the influence of shading for the attractiveness

383 of dead wood (Hjältèn et al., 2007). Our results show slight interaction effects

384 between trap attractant and trap environment. A very moderate bait-openness

385 interaction effect was measured, whereas trap attractiveness appeared to be reduced

386 in an alcohol-saturated environment, through a disruption by local fresh dead-wood

387 concentrations of the kairomonal response of saproxylic beetles to baited traps

388 ('alcohol disruption').

389 In accordance with these results and although alcohol-baited traps appeared to be

390 more efficient than unbaited devices, we recommend to take care to use baited

391 brine or glycol solution used as a preservative fluid does not vary with forest stands.

392 Beside the attractant, other trap parameters, such as colour and shape, should be 393 assessed for optimization and standardization and have been partly examined in 394 another study (Bouget et al., in press). 
395 Acknowledgements

396

397 We would like to thank the French National Forest Service (ONF) for funding a part

398 of the analytical work. Victoria Moore and 3 anonymous reviewers deeply improved

399 the first drafts of the manuscript. Many thanks to Hélène Barbareau for technical

400 assistance. We are also grateful to several amateur entomologists who helped with

401 beetle identification. This research was mainly funded by the European Regional

402 Development Fund (ERDF) and the French National Hunting and Wildlife Office

403 (ONCFS).

404 
406 Alinvi, O., Ball, J., Danell, K., Hjältén, J. \& Pettersson, R. (2007) Sampling the

407 saproxylic beetle community in dead wood logs: comparing window and eclector

408 traps to traditional bark sieving and a refinement. Journal of Insect Conservation, 11,

409 99-112.

410 Berti, F. \& Flechtmann, C. (1986) A model of ethanol trap to collect Scolytidae and

411 Platypodidae (Insecta, Coleoptera). Revista Instituto de Pesquisas e Estudos 412 Florestais, 34, 53-56.

413 Bouget, C., Brustel, H., Brin, A. \& Noblecourt, T. (in press) Sampling saproxylic 414 beetles with window flight traps: methodological insights. Terre et Vie, Revue 415 d'écologie

416 Brockerhoff, E., Jones, D., Kimberley, M., Suckling, D. \& Donaldson, T. (2006)

417 Nationwide survey for invasive wood-boring and bark beetles (Coleoptera) using 418 traps baited with pheromones and kairomones. Forest Ecology and Management, $419228,234-240$.

420 Brustel, H. (2004) "Polytrap"TM" a window flight trap for saproxylic beetles. 3rd 421 Symposium and Workshop on the Conservation of Saproxylic Beetles, Riga (Latvia), 422 7th-11th July, 2004. Poster

423 Byers, JA. (1992) Attraction of bark beetles, Tomicus piniperda, Hylurgops 424 palliatus, and Trypodendron domesticum and other insects to short chain alcohols 425 and monoterpenes. Journal of Chemical Ecology, 18, 2385-2402.

426 Byers, J.A. (1989) Chemical ecology of bark beetles. Experientia, 45, 271-283

427 Cade, S., Hrutfiord, B. \& Gara, R. (1970) Gnathotrichus sulcatus (Coleoptera: 428 Scolytidae): identification of a primary attractant. Journal of Economic Entomology, 429 63, 1014-1015. 
430 Chapman, J. A. \& Kinghorn, J. M. (1955) Window flight traps for insects. Canadian

$431 \quad$ Entomologist, 87, 46-47.

432 Chénier, J.V.R. \& Philogène, B.J.R. (1989) Field responses of certain forest

433 Coleoptera to conifer monoterpenes and ethanol. Journal of Chemical Ecology, 15,

$434 \quad 1729-1745$

435 Clarke, K.R. (1993) Non-parametric multivariate analyses of changes in community 436 structure. Australian Journal of Ecology, 18, 117-143.

437 Döring, E. (1955) Zur Biologie des grossen Eichenbockkäfers (Cerambyx cerdo L.)

438 unter besonderer Berücksichtigung der Populationsbewegungen im Areal. Zeitschrift

439 Angewandte Zoologie, 42, 251-373.

440 Hjältén, J., Johansson, T., Alinvi, O., Ball, J., Danell, K., Pettersson, R., Gibb, H. \& 441 Hilszczanski, J. (2007) The importance of substrate type, shading and scorching for 442 the attractiveness of dead wood to saproxylic beetles. Basic and Applied Ecology, 8, $443 \quad 364-376$.

444 Honek, A. (1988) The effect of crop density and microclimate on pitfall trap catches 445 of Carabidae, Staphylinidae (Coleoptera) and Lycosidae (Araneae) in cereal fields. 446 Pedobiologia, 32, 233-242.

447 Jonsell, M., Schroeder, M. \& Larsson, T. (2003) The saproxylic beetle Bolitophagus 448 reticulatus: its frequency in managed forests, attraction to volatiles and flight period. 449 Ecography, 26, 421-428.

450 Kimmerer, T. \& Kozlowski, T. (1982) Ethylene, ethane, acetaldehyde and ethanol 451 production by plants under stress. Plant Physiology, 69, 840-847.

452 Leather, S. (2005) Insect Sampling in Forest Ecosystems. Blackwell Science, 320 p. 
453 Lindelöw, Å., Risberg, B. \& Sjödin, K. (1992) Attraction during flight of scolytids

454 and other bark- and wood-dwelling beetles to volatiles from fresh and stored spruce 455 wood. Canadian Journal of Forest Research, 22, 224-228.

456 Magema, N, Gaspar, C. \& Séverin, T. (1982) Efficacité de l'éthanol dans le piégeage 457 du scolyte Trypodendron lineatum (Olivier, 1795)(Coleoptera, Scolytidae) et rôle des 458 constituants terpéniques de l'épicéa. Annales de la Société Royale de Zoologie de 459 Belgique, 112, 49-60.

460 McIntosh, R. L., Katinic, P. J., Allison, J. D., Borden, J. H. \& Downey, D. L. (2001)

461 Comparative efficacy of five types of trap for woodborers in the Cerambycidae, 462 Buprestidae and Siricidae. Agricultural and Forest Entomology, 3, 113-120.

463 Montgomery, M.E., \& Wargo, P.M. (1983) Ethanol and other host-derived volatiles 464 as attractants to beetles that bore into hardwoods. Journal of Chemical Ecology, $4659: 181-190$.

466 Nilsson, S.G., Hedin, J. \& Niklasson, M. (2001) Biodiversity and its assessment in 467 boreal and nemoral forests. Scandinavian Journal of Forest Research, Suppl. 3, 1046826.

469 Nordlander, G., Eidmann, H. H., Jacobsson, U., Nordenhem, H. \& Sjödin, K. (1986) 470 Orientation of the pine weevil Hylobius abietis to underground sources of host 471 volatiles. Entomologia Experimentalis Applicata, 41, 91-100.

472 Økland, B. (1996) A comparison of three methods of trapping saproxylic beetles.

473 European Journal of Entomology, 93, 195-209.

474 Peck, S. B. \& Davies, A. E. (1980) Collecting small beetles with large area window 475 traps. The Coleopterists Bulletin, 34, 237-239.

476 Pinheiro, J.C. \& Bates, D.M. (2000) Mixed-effects models in S and S-PLUS. 477 Springer, New York. 
478 Poland, T.M., Haack, R.A. \& Petrice, T.R. (2004) Evaluation of three trap types and

479 five lures for monitoring Hylurgus ligniperda (Coleoptera: Scolytidae) and other

480 local scolytids in New York. Great Lakes Entomologist, 37 (No. 1/2), 1-9

481 Roling, M. P. \& Kearby, W. H. (1975) Seasonal flight and vertical distribution of

482 Scolytidae attracted to ethanol in an oak-hickory forest in Missouri. Canadian

483 Entomologist, 107, 1315-1320

484 Ruther, J., Meiners, T. \& Steidle, J. (2002) Rich in phenomena-lacking in terms. A

485 classification of kairomones. Chemoecology, 12, 161-167.

486 Schroeder, L. \& Lindelöw, A. (1989) Attraction of scolytids and associated beetles

487 by different amounts and proportions of alpha pinene and ethanol. Journal of 488 Chemical Ecology, 15, 807-817.

489 Schroeder, L.M. (2003) Differences in responses to $\alpha$-pinene and ethanol, and flight 490 periods between the bark beetle predators Thanasimus femoralis and T. formicarius 491 (Col.: Cleridae). Forest Ecology and Management, 177, 1-3, 7, 301-311

492 Shibata, E., Sato, S., Sakuratani, Y., Sugimoto, T., Kimura F. \& Ito F. (1996)

493 Cerambycid beetles (Coleoptera) lured to chemicals in forests of Nara prefecture,

494 Central Japan. Ecology and Population Biology, 89, 6, 835-842.

495 Siitonen, J. (2001) Forest management, coarse woody debris and saproxylic 496 organisms : Fennoscandian boreal forests as an example. Ecological Bulletins, 49, $497 \quad 11-41$.

498 Siitonen, J. (1994) Decaying wood and saproxylic Coleoptera in two old spruce 499 forests: a comparison based on two sampling methods. Annales Zoologici Fennici, $500 \quad 31,89-95$.

501 Speight, M.C.D. (1989) Les invertébrés saproxyliques et leur protection. Conseil de 502 l'Europe, Strasbourg. 
503 Sweeney, J., De Groot, P., MacDonald, L., Smith, S., Cocquempot, C., Kenis, M. \&

504 Gutowski, J.M. (2004) Host volatile attractants and traps for detection of Tetropium

505 fuscum (F.), Tetropium castaneum L., and other longhorned Beetles (Coleoptera :

506 Cerambycidae). Environmental Entomology, 33, 4, 844-854

507 Wikars, L.O., Sahlin, E. \& Ranius, T. (2005) A comparison of three methods to

508 estimate species richness of saproxylic beetles (Coleoptera) in logs and high stumps

509 of Norway spruce. Canadian Entomologist, 137, 304-324.

510 
$511 \quad$ Figure legends

512

$513 \quad$ Figure 1

514 Design of the cross-vane window flight trap used during the study

516 Figure 2

517 NMDS ordination plot of the Bray-Curtis dissimilarity matrix of baited (AL) and

518 unbaited (NAL) samples. The two axes with highest correlation to bait factor are

519 represented. 4 -dimension stress $=0.153$. ANOSIM test $(10000$ permutations $)$

520 confirmed the difference of assemblages $(R=0.65, \mathrm{p}<0.0001)$.

521

522 Figure 3

523 Mean abundance (a) and species richness (b) per trap of saproxylic beetles in baited

524 (AL) and unbaited (NAL) traps in open (MO) or closed-canopy (MF) stands. Linear 525 mixed-model ANOVA F-test significance of the interaction effect between bait and 526 openness: $* * \mathrm{p}<0.01, * 0.01<\mathrm{p}<0.05, \mathrm{~ns} \mathrm{p}>0.05$

$528 \quad$ Figure 4

529 Mean difference in abundance per trap of saproxylic beetle families (a) and species

530 (b) between baited (AL) and unbaited (NAL) traps in open (MO) or closed-canopy

531 (MF) stands. Mann-Whitney test significance: $* * p<0.01, * 0.01<\mathrm{p}<0.05$, ns $\mathrm{p}>0.05$.

532 Only species and families including more than 30 individuals were tested.

534 Figure 5 
535 Mean species richness (a) and abundance (b) per trap of saproxylic beetles in baited

536 (AL) and unbaited (NAL) traps in fresh dead wood poor stands [forest controls (F)

537 and ancient gaps (TA)] and fresh dead wood rich stands [recent gaps (TR)]. Linear

538 mixed-model ANOVA test significance: $* * \mathrm{p}<0.01, * 0.01<\mathrm{p}<0.05, \mathrm{~ns} \mathrm{p}>0.05$.

539 Mean difference in richness (c) and abundance (d) between baited and unbaited traps

540 in fresh dead wood poor stands [F, TA] and fresh dead wood rich stands [TR].

541 Different letters indicate significant differences between means after a post-hoc

542 Tukey test $(\mathrm{p}=0.01)$.

544 Figure 6

545 Mean difference in abundance per trap of saproxylic beetle families (a) and species

546 or genera (b) between baited and unbaited traps in fresh dead wood poor stands

547 [forest controls (F) and ancient gaps (TA)] and fresh dead wood rich stands [recent

548 gaps (TR)]. Linear mixed-model ANOVA test significance: ** $\mathrm{p}<0.01$, *

$5490.01<\mathrm{p}<0.05$, ns $\mathrm{p}>0.05$. Different letters indicate significant differences between

550 means after a post-hoc Tukey test $(\mathrm{p}=0.01)$. Only species and families including

551 more than 30 individuals were tested. 
557 Differences between baited (AL) and unbaited (NAL) traps, in terms of saproxylic 558 beetle abundance, species richness. Test significance: $* * \mathrm{p}<0.01, * 0.01<\mathrm{p}<0.05$, ns $559 \mathrm{p}>0.05$. Differences were tested by linear mixed-model ANOVA F-tests. Mean 560 values are expressed +/- Standard Deviation.

561

\begin{tabular}{|l|l|l|l|}
\hline \multicolumn{1}{|c|}{ Taxa } & \multicolumn{1}{|c|}{ Alcohol-baited traps } & \multicolumn{1}{|c|}{ Unbaited traps } & \\
\hline Abundance & $331,417+/-156,330$ & $143,750+/-55,155$ & $F_{(1,23)}=66,482$ ** \\
\hline Species richness & $43,125+/-9,768$ & $31,458+/-8,827$ & $F_{(1,23)}=68,649 * *$ \\
\hline
\end{tabular}


565 Mean abundance per trap of saproxylic beetle species and families in baited (AL) and 566 unbaited (NAL) traps. Linear mixed-model ANOVA test significance: ** $\mathrm{p}<0.01$, * $567 \quad 0.01<\mathrm{p}<0.05$, ns $\mathrm{p}>0.05$. Mean values are expressed $+/$ - Standard Deviation.

568 569

\begin{tabular}{|c|c|c|c|}
\hline Taxa & Alcohol-baited traps & Unbaited traps & $F_{(1,23)}{ }^{p}$ \\
\hline LEIODIDAE & $1,125+/-1,424$ & $1,625+/-2,123$ & $\mathrm{~F}=1,274^{\mathrm{ns}}$ \\
\hline STAPHYLINIDAE & $49,458+/-28,290$ & $34,667+/-19,325$ & $F=15,243$ ** \\
\hline Aleochara sparsa & $1,833+/-1,711$ & $0,167+/-0,637$ & $F=27,688^{* *}$ \\
\hline Eusphalerum angustum & $29,542+/-26,132$ & $30,500+/-19,638$ & $\mathrm{~F}=1,908^{\mathrm{ns}}$ \\
\hline Paraphloeostiba gayndahense & $9,958+/-8,175$ & $0,375+/-0,576$ & $F=198,854$ ** \\
\hline Leptusa pulchella & $0,958+/-1,301$ & $0,500+/-0,780$ & $\mathrm{~F}=1,929^{\mathrm{ns}}$ \\
\hline LUCANIDAE & $0,625+/-0,824$ & $0,833+/-1,007$ & $\mathrm{~F}=0,512^{\mathrm{ns}}$ \\
\hline Sinodendron cylindricum & $0,542+/-0,658$ & $0,750+/-0,847$ & $\mathrm{~F}=0,682^{\mathrm{ns}}$ \\
\hline EUCNEMIDAE & $1,250+/-2,345$ & $0,667+/-1,049$ & $\mathrm{~F}=0,414^{\mathrm{ns}}$ \\
\hline Melasis buprestoides & $1,250+/-2,345$ & $0,667+/-1,049$ & $\mathrm{~F}=0,467^{\mathrm{ns}}$ \\
\hline ELATERIDAE & $1,667+/-1,903$ & $2,292+/-1,944$ & $\mathrm{~F}=1,422^{\mathrm{ns}}$ \\
\hline Idolus picipennis & $0,917+/-1,501$ & $1,375+/-1,610$ & $\mathrm{~F}=2,293^{\mathrm{ns}}$ \\
\hline ANOBIIDAE & $26,500+/-22,043$ & $24,042+/-22,160$ & $\mathrm{~F}=0,141^{\mathrm{ns}}$ \\
\hline Grynobius planus & $0,917+/-1,558$ & $1,167+/-2,160$ & $\mathrm{~F}=0,012^{\mathrm{ns}}$ \\
\hline Hemicoelus costatus & $7,292+/-8,961$ & $7,250+/-7,731$ & $\mathrm{~F}=0,000^{\mathrm{ns}}$ \\
\hline Ptilinus pectinicornis & $16,500+/-20,061$ & $12,458+/-15,704$ & $\mathrm{~F}=0,280^{\mathrm{ns}}$ \\
\hline Ptinomorphus imperialis & $0,458+/-0,932$ & $0,958+/-3,458$ & $\mathrm{~F}=0,043^{\mathrm{ns}}$ \\
\hline Xestobium plumbeum & $1,333+/-1,494$ & $2,083+/-5,579$ & $F=0,209^{n s}$ \\
\hline LYMEXYLIDAE & $6,333+/-10,639$ & $0,375+/-1,279$ & $F=38,526^{* *}$ \\
\hline Hylecoetus dermestoides & $6,333+/-10,639$ & $0,375+/-1,279$ & $F=41,528$ ** \\
\hline CLERIDAE & $0,917+/-1,283$ & $1,042+/-1,459$ & $\mathrm{~F}=0,053^{\mathrm{ns}}$ \\
\hline Tillus elongatus & $0,917+/-1,283$ & $1,042+/-1,459$ & $\mathrm{~F}=0,125^{\mathrm{ns}}$ \\
\hline MELYRIDAE & $12,792+/-12,646$ & $8,875+/-8,295$ & $\mathrm{~F}=0,617^{\mathrm{ns}}$ \\
\hline MALACHIIDAE & $2,000+/-2,537$ & $3,292+/-3,196$ & $\mathrm{~F}=3,651^{\mathrm{ns}}$ \\
\hline MONOTOMIDAE & $2,417+/-2,263$ & $0,250+/-0,442$ & $F=60,460$ ** \\
\hline Rhizophagus spp. & $2,375+/-2,281$ & $0,167+/-0,381$ & $F=57,873^{* *}$ \\
\hline CRYPTOPHAGIDAE & $14,625+/-14,984$ & $5,917+/-5,823$ & $F=17,544^{* *}$ \\
\hline Cryptophagus spp. & $14,125+/-15,103$ & $5,833+/-5,880$ & $F=14,091 * *$ \\
\hline LATRIDIIDAE & $8,625+/-6,851$ & $6,000+/-5,703$ & $F=3,009^{n s}$ \\
\hline MYCETOPHAGIDAE & $1,750+/-1,539$ & $1,042+/-1,083$ & $\mathrm{~F}=2,757^{\mathrm{ns}}$ \\
\hline CIIDAE & $5,667+/-5,346$ & $5,208+/-5,073$ & $\mathrm{~F}=0,143^{\mathrm{ns}}$ \\
\hline TETRATOMIDAE & $3,583+/-3,202$ & $2,625+/-3,609$ & $\mathrm{~F}=4,037^{\mathrm{ns}}$ \\
\hline Tetratoma ancora & $3,583+/-3,202$ & $2,625+/-3,609$ & $\mathrm{~F}=4,037^{\mathrm{ns}}$ \\
\hline MELANDRYIDAE & $2,250+/-2,592$ & $1,542+/-1,615$ & $\mathrm{~F}=1,850^{\mathrm{ns}}$ \\
\hline Melandrya caraboides & $0,958+/-1,398$ & $0,792+/-1,285$ & $\mathrm{~F}=0,456^{\mathrm{ns}}$ \\
\hline MORDELLIDAE & $1,333+/-3,199$ & $1,083+/-1,909$ & $\mathrm{~F}=0,337^{\mathrm{ns}}$ \\
\hline Tomoxia bucephala & $0,917+/-2,586$ & $0,917+/-1,886$ & $\mathrm{~F}=0,316^{\mathrm{ns}}$ \\
\hline SALPINGIDAE & $89,417+/-44,071$ & $3,417+/-2,165$ & $F=162,552$ ** \\
\hline Rabocerus foveolatus & $4,750+/-3,650$ & $0,208+/-0,588$ & $F=82,129$ ** \\
\hline Rhinosimus planirostris & $53,167+/-25,426$ & $1,583+/-1,248$ & $F=486,084$ ** \\
\hline Rhinosimus ruficollis & $31,458+/-18,967$ & $1,583+/-1,472$ & $F=201,812^{\text {** }}$ \\
\hline SCRAPTIIDAE & $2,292+/-2,510$ & $2,458+/-1,719$ & $\mathrm{~F}=1,540^{\mathrm{ns}}$ \\
\hline Anaspis rufilabris & $1,417+/-1,213$ & $1,792+/-1,587$ & $\mathrm{~F}=0,428^{\mathrm{ns}}$ \\
\hline CERAMBYCIDAE & $10,375+/-7,471$ & $9,792+/-7,396$ & $\mathrm{~F}=0,042^{\mathrm{ns}}$ \\
\hline Clytus arietis & $1,625+/-2,143$ & $1,042+/-1,654$ & $\mathrm{~F}=2,878^{\mathrm{ns}}$ \\
\hline Oxymirus cursor & $1,625+/-2,018$ & $1,542+/-1,250$ & $\mathrm{~F}=0,065^{\mathrm{ns}}$ \\
\hline Rhagium bifasciatum & $3,542+/-3,176$ & $3,958+/-3,862$ & $\mathrm{~F}=0,007^{\mathrm{ns}}$ \\
\hline Rhagium mordax & $1,417+/-1,349$ & $1,667+/-2,160$ & $\mathrm{~F}=0,005^{\mathrm{ns}}$ \\
\hline SCOLYTIDAE & $81,417+/-127,180$ & $22,583+/-21,040$ & $F=23,698^{* *}$ \\
\hline Ernoporicus caucasicus & $18,667+/-37,632$ & $4,417+/-4,452$ & $F=10,469^{* *}$ \\
\hline Taphrorychus bicolor & $53,083+/-125,971$ & $17,208+/-20,121$ & $\mathrm{~F}=0,586^{\mathrm{ns}}$ \\
\hline Xyleborus saxesenii & $4,792+/-3,683$ & $0,042+/-0,204$ & $F=107,812$ ** \\
\hline Xyloterus domesticus & $2,000+/-2,284$ & $0,125+/-0,448$ & $F=22,674^{* *}$ \\
\hline Xyloterus signatus & $1,792+/-2,021$ & $0,000+1-0,000$ & $F=32,427^{* *}$ \\
\hline
\end{tabular}


$570 \quad$ Figures

571

572 Figure 1

573

574
575

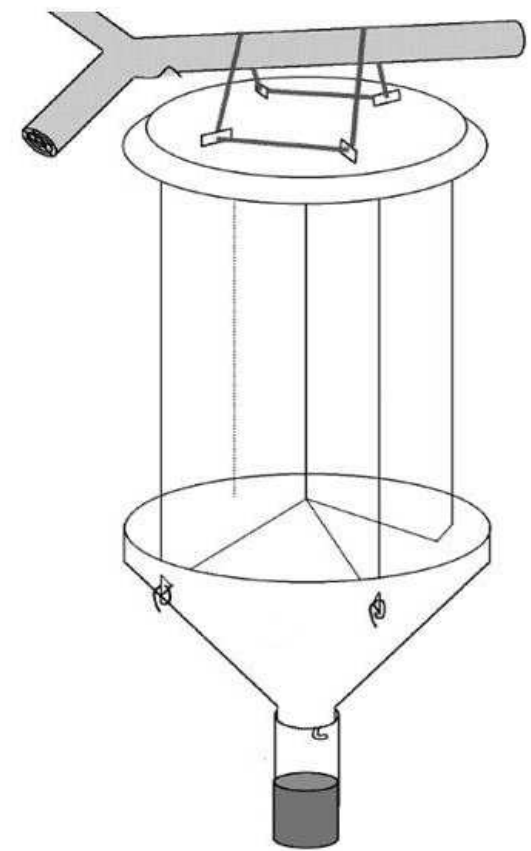


576 Figure 2

577

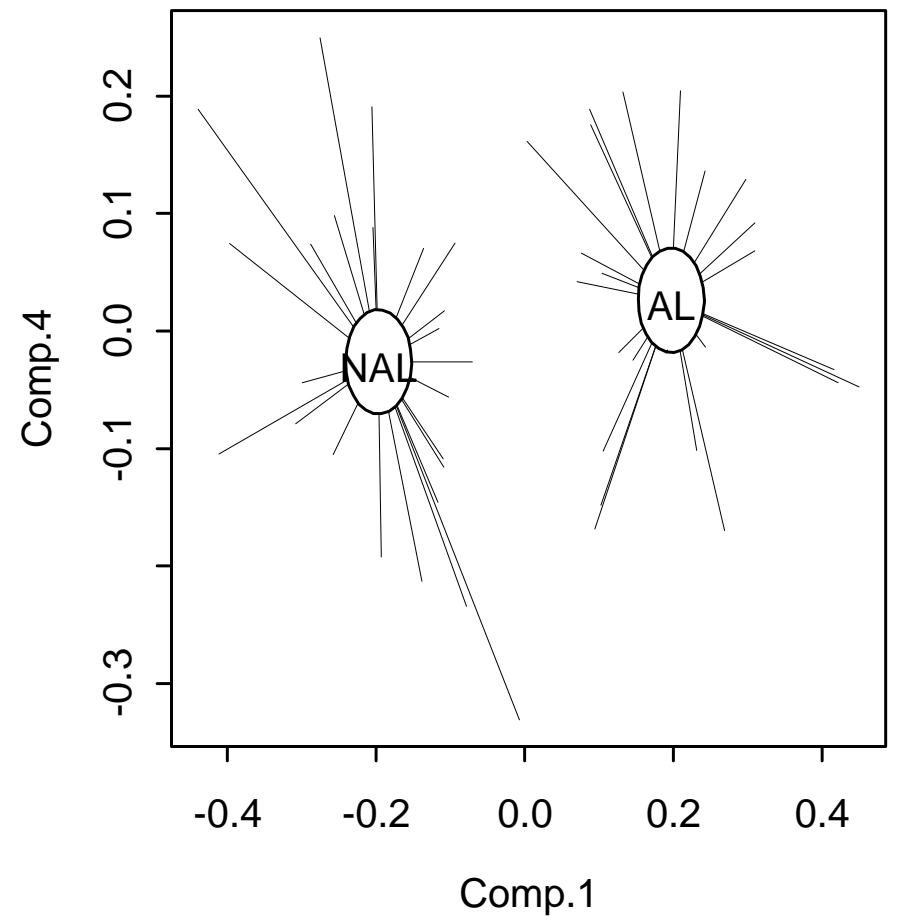


$578 \quad$ Figure 3

579

(a)

(b)

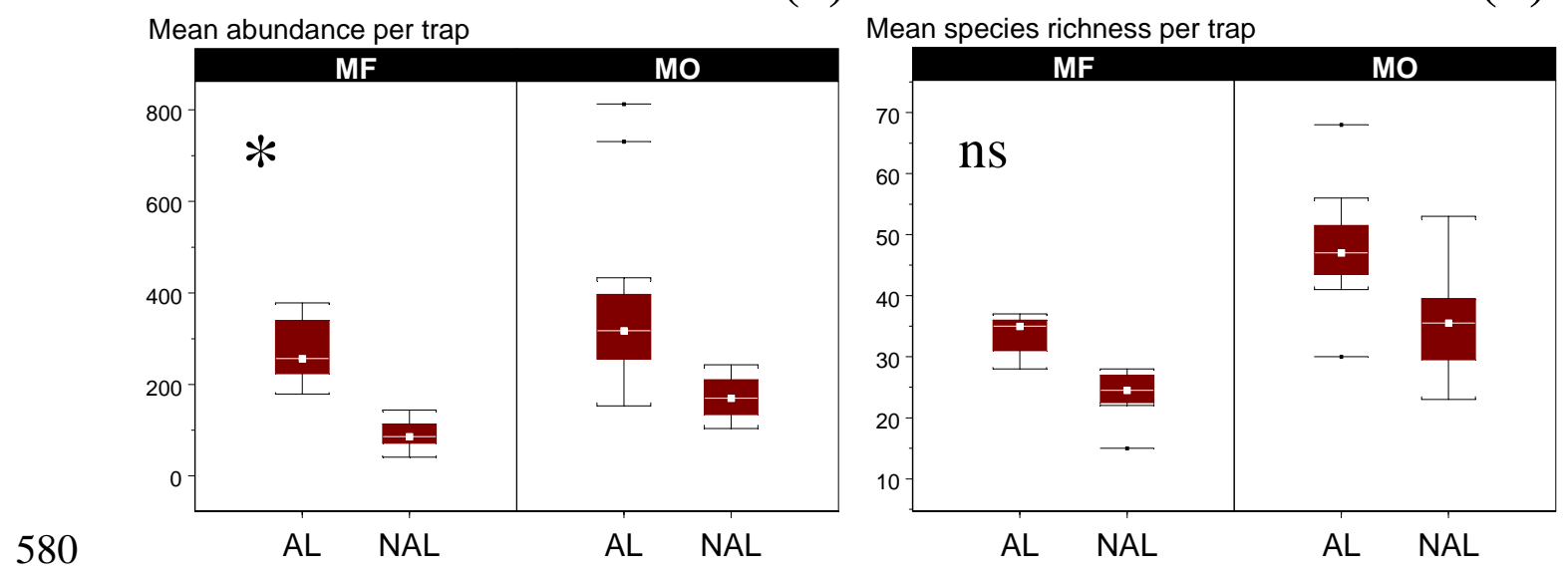


Figure 4

582

583

584

(a) Families

Difference in abundance
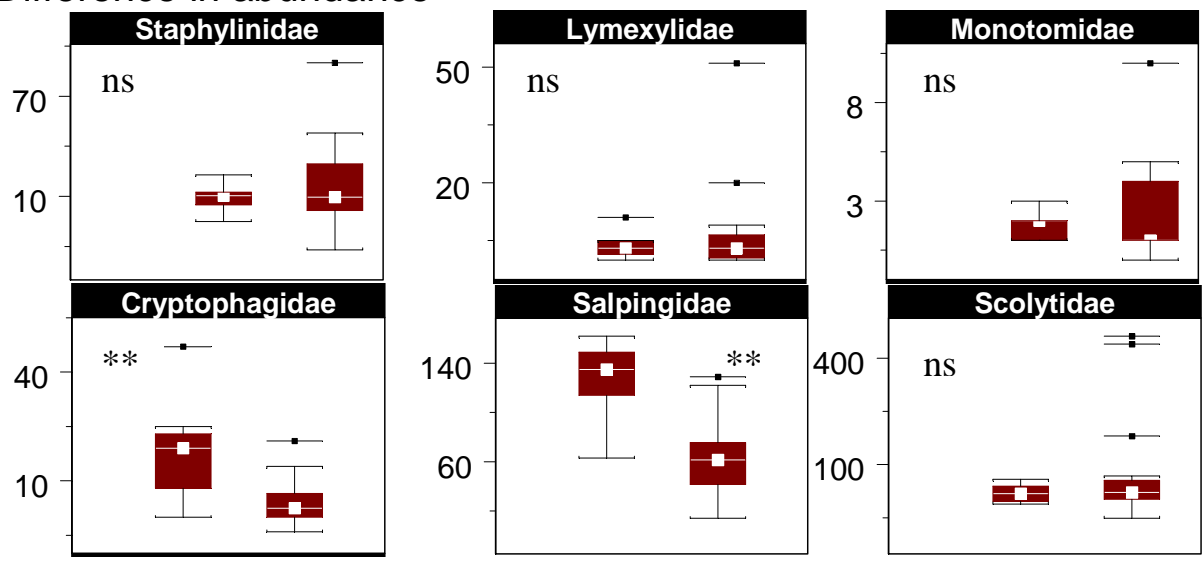

(b) Species

Difference in abundance
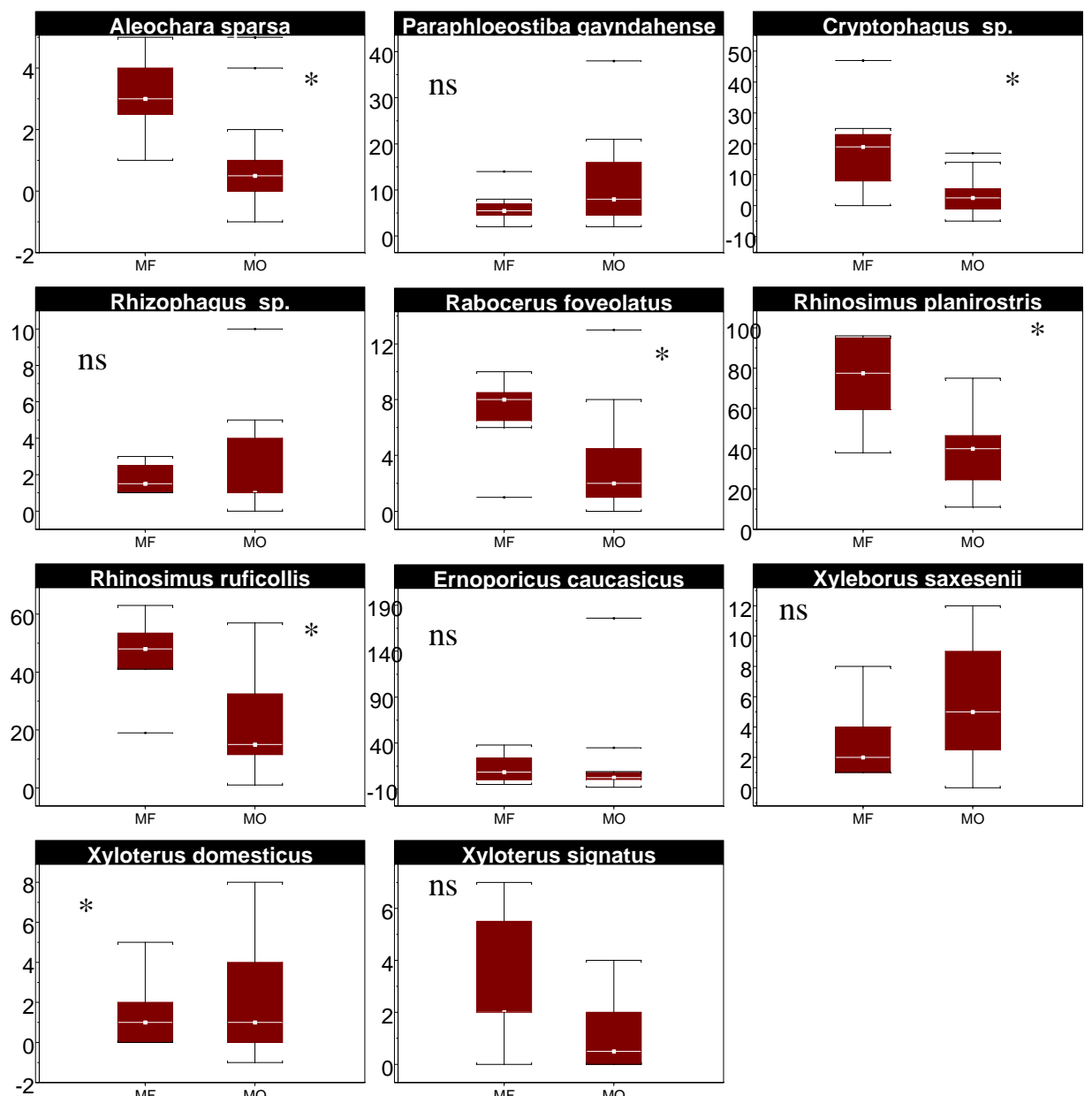
587

Figure 5

588
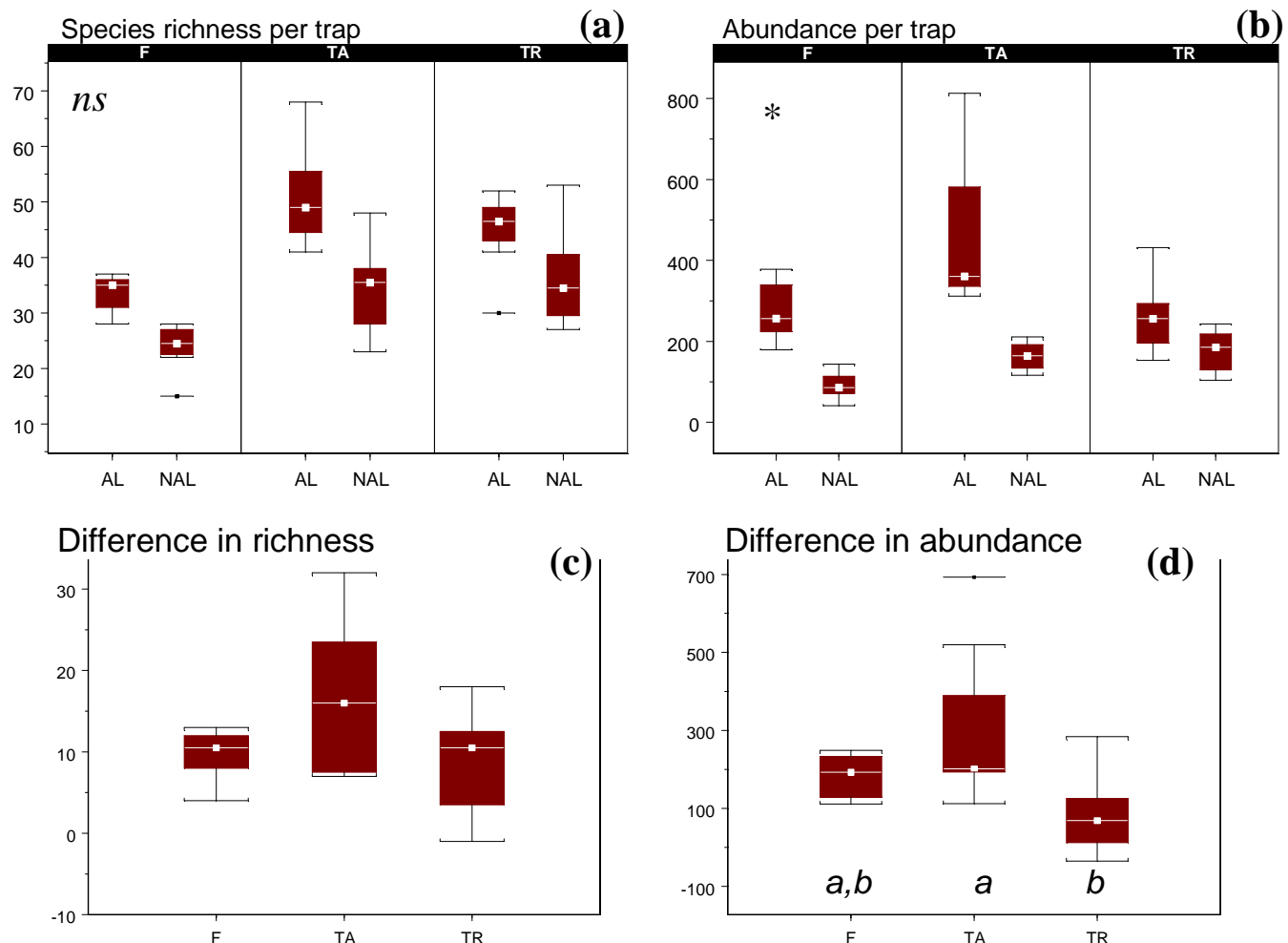
$591 \quad$ Figure 6

592

(a) Families

Differences in abundance


(b) Species

Differences in abundance

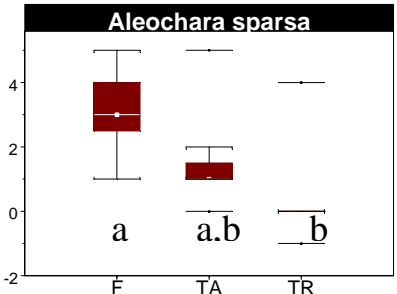

Paraphloeostiba gayndahense

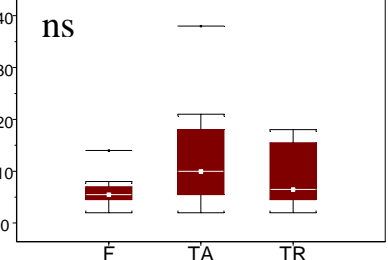

Cryptophaqus sp


Xyloterus domesticus

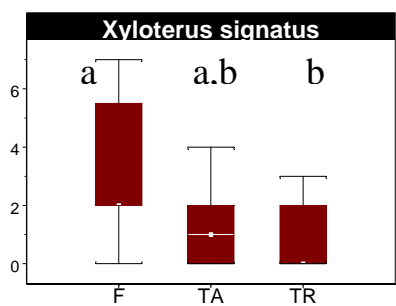

593

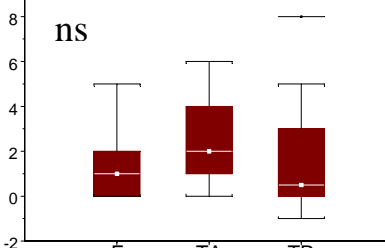

594 